\title{
A Literature Review on the Sleeper and Cross-Body Horizontal Adduction Stretching
}

\author{
Young Jin Jo', Young Kyun Kim²* \\ ${ }^{1}$ Galaxia SM Inc, Seoul, Republic of Korea \\ ${ }^{2}$ Sports, Health, and Rehabilitation Major, Kookmin University, Republic of Korea
}

\author{
Received: October 9, 2019 \\ Accepted: October 28, 2019 \\ Published online: October 31, 2019
Keywords: Deficit(GIRD)
Overhead Athlete
Posterior Shoulder Tightness \\ Glenohumeral Internal Rotation \\ Sleeper Stretch
}
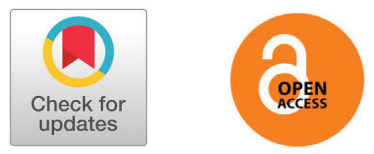

\section{ABSTRACT}

OBJECTIVES Overhead throwing athlete's glenohumeral internal rotation deficit (GIRD) and posterior shoulder tightness (PST) could increase the risk of shoulder injuries. Sleeper stretching and cross-body stretching has shown the effect of improved PST and increased internal rotation in overhead throwing athletes. The purpose of this study is to provide how to apply those stretching techniques in evidence-based method to improve the effects of the stretching on throwing athletes.

METHODS We searched total 1650 research with keywords related. Then we selected 60 research which applied randomized control trials (RCTs). We then reviewed and selected 9 research out of 18 research to review the stretching techniques

RESULTS Sleeper stretching and cross-body stretching techniques were applied for 30 seconds with 3 to 5 repetitions showing positive results. Additionally, applying scapular stabilization and joint mobilization with those stretching techniques showed more improved effects.

CONCLUSIONS To prevent and treat GIRD and PST, sleeper stretching and cross-body stretching are recommended on throwing athletes with scapular stabilization and joint mobilization.

(c) The Asian Society of Kinesiology and the Korean Academy of Kinesiology
서론

어깨안쪽돌림결핍(Glenohumeral Internal Rotation Deficit; GIRD)과 어깨후방구축(Posterior Shoulder Tightness; PST)은 야구, 테니스, 핸드볼, 저항 운동과 같은 오버헤드 스포츠 참가자들에게 발생되는 어깨 손 상의 주된 원인으로 알려져 있다[1-4]. Burkhart 등 [2] 은 비 주축 어깨와 비교하여 주축에서의 제한된 어깨 안 쪽 돌림을 GIRD로 처음 용어를 정립하였다. 이후 다양 한 연구들을 통해서 GIRD에 영향을 주는 신체적 특성 과 GIRD가 어깨 손상에 미치는 영향에 대해 조사되었 다[5,6]. GIRD의 원인이 되는 신체적 특성으로는 위팔

*Correspondence: Young Kyun Kim, Sports, Health, and Rehabilitation Major, Kookmin University, Jeongneungro 77, Seongbuk-gu, Seoul, Korea; Tel: +82-2-910-6435; E-mail: ykkim2016@kookmin.ac.kr
뼈 후경 [4], 어깨 후방의 돌림근개 근육의 단축[6,7], 어깨 후방 관절 주머니 구축[8]이 제시되었다. 또한, 어 깨 벌림 $90^{\circ}$, 팔꿈치 굽힘 $90^{\circ}$ 에서 측정된 $\mathrm{GIRD}$ 의 주 된 원인으로는 후방 관절 주머니의 구축을 보고하였다 [4,6-8]. 어깨 후방 구축 또한 감소된 어깨 안쪽 돌림 을 유발하며 어깨 손상과 깊은 연관이 있는 것으로 조사 되었다[9]. 이것은 어깨 관절의 변화된 운동학을 야기 하는 것으로 조사 되어있으며, 감소된 안쪽 돌림 및 수 평 모음, 굽힘, 증가된 바깥 돌림을 만들어 내는 것으로 보고되었다[2]. 나아가 이와 같은 위팔위목관절의 신체 적 특성은 어깨충돌증후군 [10], 어깨관절와순파열 [11], 봉우리밑충돌증후군 [12], 어깨 전방 자세 [5], 돌림근 개 근력 결함[13]을 초래할 수 있을 것으로 알려졌다 [5,10-13]. 이러한 주된 어깨 손상을 야기하는 원인을 
해결하기 위하여 다양한 중재 방법이 제시되어 오고 있 다. 어깨 안쪽 돌림 결핍과 어깨 후방 구축을 완화하는 방법으로 슬리퍼 스트레칭(Sleeper stretching) 및 몸 통 교차 수평 모음 스트레칭(Cross-body stretching) 에 대한 연구가 진행되어 왔으며 이에 대한 효과가 증명 되었다. 하지만 각각의 연구들은 대상자, 스트레칭 적용 방법, 시간 등에 차이가 있어 이에 대한 종합적으로 분 석하는 연구가 필요하다고 판단된다. 그러므로 이 논문 의 목적은 슬리퍼 스트레칭 및 몸통 교차 수평 모음 스 트레칭 운동<Figure $1>$ 이 어깨 안쪽 돌림 결핍과 어깨 후방 구축에 미치는 효과에 관한 다양한 선행 연구들을 찾아내 체계적 고찰을 통한 과학적 근거 자료의 기초를 제공하는 데 있다.
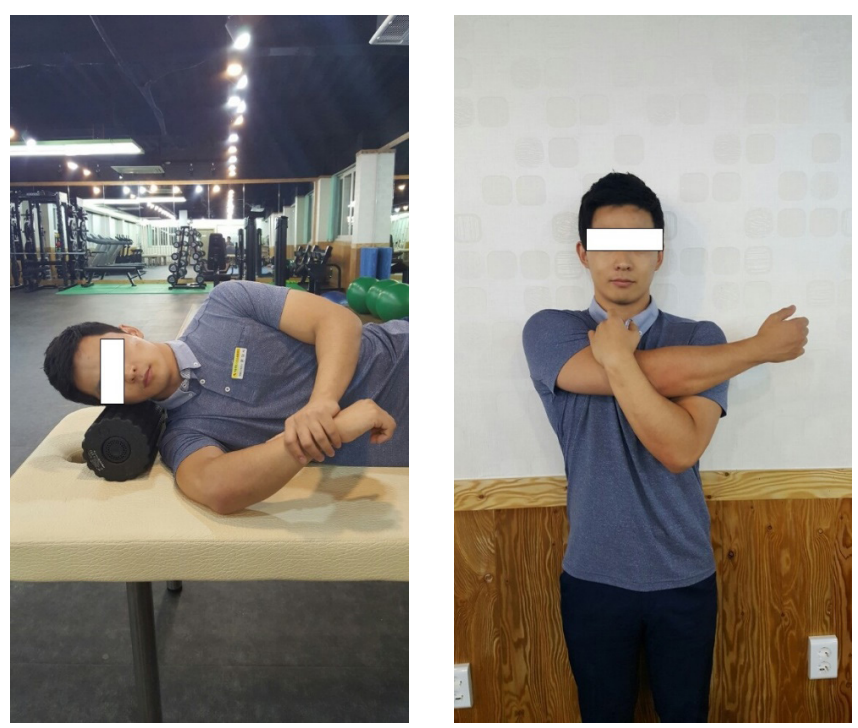

Figure 1. Cross body stretching for GIRD and PST (a) and sleeper stretching for GIRD and PST (b)

\section{연구방법}

\section{데이터베이스 검색 및 선정 기준}

본 연구를 위한 연구방법은 PLISMA guideline(Preferred Reporting Items for Systematic Reviews and Meta-Analyses statement guidelines) 의 체계적 고찰 연구 방법을 수정 변경하여 실시하였 다[14].

\section{연구의 포함기준}

선행 연구의 선정을 위하여 2006년 2016년까지 지난 10여 년간 수행된 연구들로 검색을 제한하였으며 실험 대조군(case-control) 연구를 포함하여 무작위대
조군 연구(Randomised Controlled Trials: RCTs)를 포함시켰다. 언어는 영어로 제한하였고 제외 기준으로 는 석/박사 학위논문을 포함하여 초록만 검색된 연구는 제외시켰다.

\section{데이터 베이스 검색}

본 체계적 고찰 연구를 수행하기 위하여 검색에 사 용된 용어는 다음과 같다.

Patient: posterior shoulder tightness, shoulder and glenohumeral internal rotation deficit or loss

Intervention: shoulder stretching, sleeper stretching, angular stretching, cross-body stretching

Comparison: overhead sports activity, control

Outcome: shoulder range of motion, shoulder flexibility

데이터 검색을 위하여 PUBMED, EMBASE의 국외 학술 검색 사이트를 이용하였다. 추가적으로 선행 연구 의 참고 문헌을 검토하여 수집하였다.

\section{연구 선택}

총 검색된 1650 건 중 1 차적으로 제목에 관련 연구 주제가 포함된 것을 선택하여 60개의 논문을 선정하였 다. 60 편의 논문 중 초록과 주제를 선별하여 총 18 편의 논문을 선정하였고 전체 논문의 내용을 검토하여 직접 적인 관련이 있는 최종적으로 9 편의 논문을 선정하였다.

\section{데이터 추출}

선정된 연구들로부터 다음과 같은 연구 특성들이 수 집되었다. 모든 피험자의 신체적 특성과 참가자 수, 스 트레칭 중재 프로그램의 빈도, 반복, 기간과 측정 방법, 최종 연구 결과를 추출하였다

\section{결과}

슬리퍼 및 몸통 교차 수평 모음 스트레칭이 어깨 안 쪽 돌림 결핍과 후방 구축에 미치는 효과에 대한 체계 적인 고찰을 위해 선정한 9 개의 논문은 <Table 1 >에 요약하였다.

\section{피험자 선정}

총 9편의 연구 중 8 편은 상지를 주로 사용하는 오버 
Table 1. Summary of stretching intervention program.

\begin{tabular}{|c|c|c|c|c|c|c|c|}
\hline & Author & $\begin{array}{l}\text { Stretching } \\
\text { duration }\end{array}$ & Frequency & Reps & Position & $\begin{array}{c}\text { scapula } \\
\text { stabilization }\end{array}$ & $\begin{array}{c}\text { Passive/ } \\
\text { Active }\end{array}$ \\
\hline 1 & $\begin{array}{l}\text { Guney et al. (2015) } \\
\text { [15] }\end{array}$ & 30 seconds & once daily & 3 reps & $\begin{array}{l}\text { Side-lying sleeper stretching, seated cross } \\
\text { body horizontal adduction stretching }\end{array}$ & $\begin{array}{l}\text { scapula } \\
\text { stabilization }\end{array}$ & $\begin{array}{l}\text { Passive, } \\
\text { active }\end{array}$ \\
\hline 2 & $\begin{array}{l}\text { Hammons et al. } \\
\text { (2015)[16] }\end{array}$ & 30 seconds & $\begin{array}{l}3 \text { times } \\
\text { per week }\end{array}$ & 5 reps & $\begin{array}{l}\text { Passive abduction } 90^{\circ} \text { internal rotation } \\
\text { in prone position, Seated cross body } \\
\text { horizontal adduction stretching }\end{array}$ & $\begin{array}{l}\text { scapula } \\
\text { stabilization }\end{array}$ & Passive \\
\hline 3 & $\begin{array}{l}\text { Laudneret al. (2008) } \\
\text { [17] }\end{array}$ & 30 seconds & immediate & 3 reps & Side-lying sleeper stretching & Body-weight & Passive \\
\hline 4 & $\begin{array}{l}\text { Maenhout et al. } \\
\text { (2012)[18] }\end{array}$ & 30 seconds & daily & 3 reps & $\begin{array}{l}\text { Side-lying sleeper stretching, Seated cross } \\
\text { body horizontal adduction stretching }\end{array}$ & Body-weight & active \\
\hline 5 & $\begin{array}{l}\text { McClure et al. (2007) } \\
\text { [19] }\end{array}$ & 30 seconds & daily & 5 reps & $\begin{array}{l}\text { Side-lying sleeper stretching, Seated cross } \\
\text { body horizontal adduction stretching }\end{array}$ & $\begin{array}{l}\text { No scapular } \\
\text { stabilization }\end{array}$ & active \\
\hline 6 & $\begin{array}{l}\text { Yamauchi et al. } \\
\text { (2016)[20] }\end{array}$ & 30 seconds & once daily & 3 reps & $\begin{array}{l}\text { Side-lying modified sleeper stretching, } \\
\text { Side-lying cross body horizontal adduction } \\
\text { stretching }\end{array}$ & Body-weight & active \\
\hline 7 & $\begin{array}{l}\text { Cools et al. (2012) } \\
{[21]}\end{array}$ & 30 seconds & $\begin{array}{l}3 \text { times } \\
\text { per week }\end{array}$ & $\begin{array}{l}\text { continue for } \\
15 \mathrm{~min}\end{array}$ & $\begin{array}{l}\text { Side-lying sleeper stretching, supine-lying } \\
\text { cross body horizontal adduction stretching } \\
\text { with joint mobilization }\end{array}$ & $\begin{array}{l}\text { scapula } \\
\text { stabilization }\end{array}$ & Passive \\
\hline 8 & $\begin{array}{l}\text { Manske et al. (2010) } \\
\text { [22] }\end{array}$ & 30 seconds & $\begin{array}{l}\text { at least once } \\
\text { daily }\end{array}$ & 5 reps & $\begin{array}{l}\text { Seated cross body horizontal adduction } \\
\text { stretching with joint mobilization }\end{array}$ & $\begin{array}{l}\text { No scapular } \\
\text { stabilization }\end{array}$ & active \\
\hline 9 & $\begin{array}{l}\text { Salamh et al. (2015) } \\
\text { [23] }\end{array}$ & 30 seconds & immediate & 3 reps & $\begin{array}{l}\text { supine-lying cross body horizontal } \\
\text { adduction stretching }\end{array}$ & $\begin{array}{l}\text { scapula } \\
\text { stabilization }\end{array}$ & passive \\
\hline
\end{tabular}

헤드 스포츠 참가자로 선정하여 그 중 어깨 안쪽 돌림 결 핍이 존재하는 피험자를 대상으로 연구가 진행되었다. 유일하게 Guney 등[15]의 연구만 주축 어깨의 내회전 가동범위가 비 주축 어깨와 비교하여 $18^{\circ}$ 미만인 성인 여성을 대상으로 하여 진행되었다. 2 편의 연구는 투구 동작의 야구 선수를 대상으로 하였다[17,20]. 그 외 나 머지 7편의 연구는 배구, 야구, 테니스, 스쿼시, 배드민 턴 등이 포함된 오버헤드 스포츠 참가자를 대상으로 진 행되었다[15,16,18,19,21-23].

\section{스트레칭 중재 프로그램}

총 9편의 선행 연구 중 독립적인 스트레칭 중재만 실 시한 연구는 6편이었으며[15-20] 나머지 2편은 스트 레칭과 관절 가동화 기법을 함께 적용하여 진행되었다 [21,22]. 어깨 안쪽 돌림 결핍과 어깨 후방 구축을 해결 하기 위한 스트레칭 종류는 기본적으로 슬리퍼 스트레칭 과 몸통 가로지르는 몸통 교차 수평 모음 스트레칭이 수 행 되었으며 공통적으로 1 세트의 구성은 30초간 유지하 는 것을 3 5회 반복하도록 하였다. Cools 등[21]의연 구에서는 스트레칭의 반복을 제시하지 않고 15 분간 스 트레칭과 휴식을 반복적으로 실시하였다고 기술하였다.

\section{스트레칭 중재 기간}

스트레칭 중재 기간은 Guney 등[15]의 연구에서는 1 주간, Cools 등[21]의 연구에서는 3주간 중재 후 어떠 한 처치 없이 3 주 후 재측정이 실시되었다. 이외 4 편의 연구는 4주간 실시되었으며[16,19,20,22] Maenhout 등[18]의 연구에서는 최장 4주간 중재 실시 후 어떠 한 치료 없이 4 주 후에 재 측정이 실시되었다. 또한 Laudner 등[17]과 Salamh 등[23]의 연구는 1회 스트 레칭의 급성 효과를 분석하였다.

\section{관절가동범위 측정 자세 및 장치}

$\mathrm{GIRD}$ 와 PST를 검사하기 위해 어깨 관절 가동범위 검사가 수행되었다. GIRD를 위해서는 총 9편의 선행 연 구 모두 등을 대고 누운 자세(supine position)에서 검 사자가 피험자의 위팔 오목 관절(glenohumeral joint) 을 어깨 벌림(shoulder adduction) 90\% 팔꿈치 굽힘 (elbow flexion) $90^{\circ}$ 자세에서 수동적으로 안쪽 돌림 하며 측정 되었다. 수평 모음 가동범위를 측정 위해서 등을 대고 누운 자세와 옆으로 누운 자세로 측정 되었 다. Guney 등[15]과 Salamh 등[23]의 연구에서 옆으 로 누운 자세에서 수평 모음을 측정하였고 나머지 연구 
에서는 등을 대고 누운 자세를 채택하여 위팔뼈의 수평 모음 관절가동범위를 측정 하였다.

\section{스트레칭 중재 프로그램의 효과}

총 9편의 연구 모두 스트레칭 참가 후 GIRD과 PST 으로 인한 관절 가동범위가 증가하는 효과가 나타났다. 특이적인 결과로는 몸통 교차 수평 모음 스트레칭만 한 그룹에서도 어깨 안쪽 돌림의 가동범위가 증가되었다 [17]

\section{논의}

본 연구에 선정된 9편의 선행 연구에서 두 종류의 스 트레칭이 어깨 안쪽 돌림 결핍을 감소시키는 효과를 만 들어내는 것으로 보고하였다. 모든 연구에서 스트레칭 기법으로 몸통을 가로질러 실시하는 몸통 교차 수평 모 음 스트레칭과 슬리퍼 스트레칭을 사용하였다. Cools 등 [21]은 이 두 가지의 스트레칭을 "angular stretching" 이 라고 명명하였다. 그 중 7편의 연구는 스트레칭 만으 로 어깨 안쪽 돌림 결핍에 긍정적인 효과를 만들어 내었 으며 [15-20,23] 나머지 2편의 논문은 관절 가동화 기 법을 함께 처방하여 유의한 효과를 나타내었다[21,22]. 스트레칭 중재의 자세는 공통적으로 옆으로 누운 자세의 슬리퍼 스트레칭과 앉아서 실시된 몸통 교차 수평 모음 스트레칭이 수행되었다. 1편의 연구에서만 배를 대고 누 운 자세(prone position)에서 수동적으로 안쪽 돌림 스 트레칭이 실시되었다[16]. 4편의 연구에서는 스트레칭 수행 중 검사자에 의한 보조가 실시되었다. 몸통 교차 수평 모음 스트레칭 중 검사자가 피험자의 견갑골 외측 연(lateral border)을 보조하여 안정화 시킨 후 스트레 칭을 실시하였으며 특히 스트레칭의 효과를 보다 효과 적으로 만들기 위하여 견갑골의 안정화를 실시해야 하 는 것을 권장 하였다 $[15,16,21,23]$. 하지만 Laudner 등 [17], Yamauchi 등[20], Maenhout 등[18]의 연구 에서는 몸통 교차 스트레칭을 실시하는 경우 체중에 의 한 수동적 안정화 기법을 사용하였으며 나머지 두 연구 [19,22]에서는 안정화 기법에 대한 언급 없이 피험자 들 개인이 스스로 스트레칭을 수행토록 지시하였다. 선 행연구에서는 공통적으로 보조를 동반한 스트레칭이 권 장된다고 보고하고 있다[15-23]. 또한 견갑골이 안정 화 되지 않은 상태에서 스트레칭 하는 것은 어깨관절뿐
만 아니라 견갑골 주변근육의 스트레칭이 동원되었을 수 있다고 보고하며 이로 인하여 실험결과에 오류를 야 기했을 수 있다고 기술하였다[19]. 그러므로 추후 연구 에서는 참가자가 자가 통제 또는 처치자가 견갑골 안정 화 기법을 적용한 스트레칭 방법에 대한 비교연구와 효 과에 대한 연구가 더욱 필요할 것으로 사료된다[23].

어깨 안쪽 돌림 결핍의 원인에 관해서는 현재까지 정확한 기전이 밝혀지지 않았다. 현재 선행된 연구에서 원인으로 제시된 기전은 크게 위팔뼈의 후경 [24,25]과 작은 원근(teres minor), 가시 아래근(infraspinatus), 어깨 세모근 후섬유(posterior deltoid)와 같은 바깥 돌 림 근육의 단축 $[1,6,26]$, 후방 관절 주머니(posterior capsule)의 구축으로 설명되고 있다[1,6,7,24-27]. 근 육이 신장하며 수축하는 것을 신장성 수축이라 부른다. 던지기와 같은 머리위로 실시하는 오버헤드 활동 중 발 생되는 높은 수준의 신장성 부하는 어깨 후방의 해부학 적 구조물에 손상을 유발한다[28]. 반복된 신장성 수축 은 등척성(isometric) 또는 단축성(concentric) 수축보 다 더욱 큰 근육 손상을 유발한다[26]. Reinold 등 [6] 은 어떠한 어깨 증상이 없는 67 명의 투수를 대상으로 스 프링 캠프 중 던지기를 수행 한 후 변화된 어깨의 관절 가동범위를 조사하였다. 측정은 어깨와 팔꿈치의 각도 가 각각 $90^{\circ}$ 에서 주축과 비 주축의 어깨 수동적 관절가 동범위를 측정한 결과 바깥 돌림 가동범위는 어떠한 변 화도 발견하지 못하였으나 던지기 훈련의 참가 후 어깨 관절 안쪽 돌림의 가동범위가 비 주축 어깨와 비교하여 $54.1^{\circ}$ 에서 $44.6^{\circ}$ 로 유의한 감소를 발견하였다. 이 연구 를 통하여 저자는 안쪽 돌림 결함의 원인을 후면 어깨의 바깥 돌림 근육일 것으로 제시하였다[6].

총 2 편의 논문에서는 단지 일회성의 스트레칭 중재 만으로도 즉각적인 안쪽 돌림 결핍의 긍정적인 효과를 만들 냈다 $[17,23]$. 앞서 언급한 바와 같이 바깥 돌림 근 육인 가시아래근, 작은원근, 후면 어깨 세모근으로 구 성되는 어깨 후면의 근육군은 후방 어깨 구축의 한 원 인으로 지목되었다. 그러므로 스트레칭 적용 후 가동범 위의 즉각적인 향상은 이러한 근육을 신장시키기 때문 인 것으로 설명될 수 있다. 한편 어깨 후방 관절 주머니 의 구축은 어깨 거상 움직임 중 위팔뼈 머리의 상방 전 위를 만들어 내고 회전축의 이동으로 말미암아 결국 봉 우리밑충돌증후군과 같은 관절의 병리학적인 병변을 일 으킨다[2]. 그러므로 제시된 두 가지의 스트레칭은 어 
깨 후방의 근육과 관절 주머니의 연부 조직을 향상시킬 수 있는 중요한 스트레칭 기법으로 현장에서 보다 쉽게 적용할 수 있을 것으로 사료된다.

한편 Cools 등[21]과 Manske 등[22]의 연구에서 는 관절 가동화(joint mobilization) 기법이 추가적으로 동원되어 주 2회 10 15분간 지속되었다. 또한 3 4주 간의 중재를 실시한 뒤 3 4 주 경과 후 재평가를 하여 어떠한 치료 없이도 효과가 지속되는지를 평가하였다 [21,22]. Cools 등[21]의 연구에서는 스트레칭 기법 을 수행한 그룹과 관절가동화 기법을 적용한 그룹을 비 교하였으며, Manske 등[22]의 연구는 스트레칭 그룹 과 스트레칭과 관절가동화 기법을 모두 적용하는 그룹 으로 나누어 실험을 진행하였다. Cools 등[21]의 연구 는 두 그룹 모두 치료직후 측정과 사후검사에서 개선된 관절가동범위를 보인 것으로 보고했다. 또한 Manske 등[22]의 연구에서는 관절가동화 기법을 함께 적용한 그룹에서 주축과 비 주축 어깨관절 간의 관절가동범위 차이가 줄어드는 결과를 보였으며 이는 4 주 후에도 지 속되었다. 이에 대해 어깨관절에 수동적으로 실시된 관 절가동기법 적용 또한 어깨 안쪽 돌림 결핍의 원인 중 하나인 관절 주머니의 구축을 향상 시킬 수 있기 때문 인 것으로 보이고 또한 장기간 효과가 지속된다고 보고 하였다 [21,22]. 이를 통해 스트레칭 기법에 관절가동 화 기법을 추가하여 적용하는 것이 효율적일 수 있다고 사료된다. 그러나 중재효과가 근육과 관절주머니 중 어 디에 영향을 미쳤는지 알 수 없다는 제한점이 존재한다. 그러므로 추후 연구에서는 후방 어깨관절주머니의 구축 에 대한 평가 방법과 이를 적극적으로 중재할 수 있는 방법을 적용할 필요가 있다.

현재까지 실시된 등을 대고 누운 자세의 안쪽 돌림 가동범위의 측정은 관절 각도계(goniometer)를 이용할 지라도 재 측정과 검사자 간 측정 신뢰도가 높은 것으로 보고되었다. 하지만 이러한 측정 방법이 어깨 안쪽 돌림 결핍의 원인이 되는 두 개의 연부 조직인 바깥 돌림 근 육과 후방 관절 주머니 중 어느 조직의 단축을 측정하 는지 확인되지 못한 채 사용되고 있다[9]. 이러한 제한 점을 보완하기 위하여 최근 어깨 후방 구축의 측정에 관 한 새로운 방법이 제시되었다[29]. Borstad 등[30]은 바깥 돌림 근육의 피로를 유발시킨 후 myotonometer 의 측정 장비를 사용하여 근육의 구축이 가동범위 자세 에 따른 영향을 측정하였다. 등을 대고 누운 자세 어깨
벌림 $90^{\circ}$ 에서 안쪽 돌림, 높은 굽힘 자세, 등을 대고 누 운 어깨 수평 모음 자세에서 모두 바깥 돌림 피로에 따 라 유의한 차이가 있는 것을 발견하였으며 어깨 후방 관절 주머니에 미치는 수동적 장력이 낮은 굴곡 자세에 서 가장 큰 것을 발견하였다. 이러한 결과를 바탕으로 <Figure 2>와 같이 어깨 굽힘 $40^{\circ}$ 에서 안쪽 돌림을 측 정하는 것이 후방 관절 주머니 검사로 보다 적절하다고 보고하였다[30]. 또한 최근 연구에서는 어깨 낮은 굽힘 자세의 안쪽 돌림 가동범위가 던지기 운동 전과 후 차 이가 없는 것으로 나타나 근육의 피로에 영향을 받지 않 으므로 이러한 측정 자세는 후방 관절주머니 구축을 측 정하기 위한 특이적 검사로 높은 신뢰도와 타당도를 증 명하였다[29]. 이것은 앞으로의 연구에서 어깨 안쪽 돌 림 결핍 가동 범위 측정을 위해서는 낮은 굽힘 $40^{\circ}$ 자세 를 포함시켜 안쪽 돌림 결핍의 원인이 후방 근육의 단 축인지 관절 주머니의 구축인지 식별하는 것이 필요하 다는 것을 암시한다. 이는 스트레칭이 어느 조직에 영 향을 미쳤는지 알 수 없다는 제한점에 대한 해결 방안 이 될 수 있을 것이다.

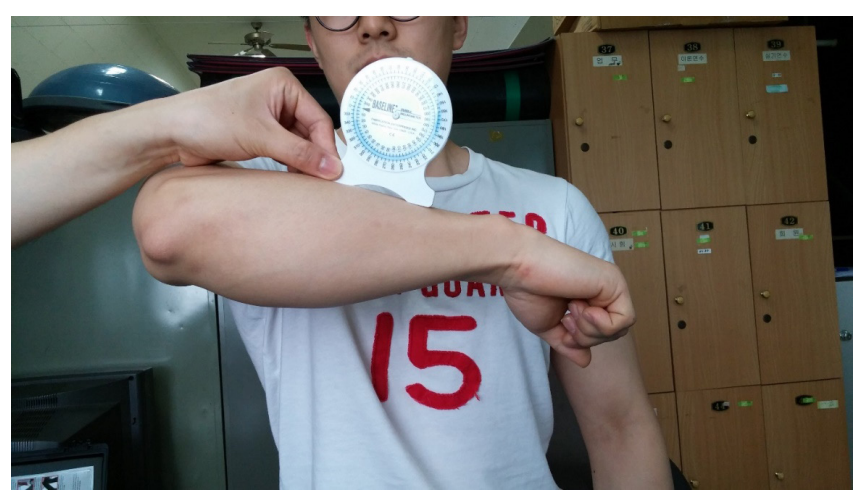

Figure 2. New measurement posterior capsule tightness

\section{결론}

어깨안쪽돌림결핍과 어깨후방구축을 해결하기 위하 여 시도된 슬리퍼 및 몸통 교차 수평 모음 스트레칭 중 재 방법은 관절가동범위 증가에 긍정적인 결과를 만들 어 낼 수 있다는 근거를 제공한 자료라고 생각된다. 특 히 오버헤드 스포츠 참가자들을 대상으로 한 상해 예방 및 재활 운동 프로그램에 두 가지 스트레칭 손상 방법 을 적용함으로써 긍정적인 효과를 만들어 낼 수 있을 것 으로 사료된다. 하지만 앞선 연구들 대부분이 검사자에 의한 보조가 동반된 스트레칭이 보다 효과적이라고 언 
급된 바 있다. 따라서 능동적으로 최적의 효과를 낼 수 있는 스트레칭을 수행할 수 있도록 이에 대한 지침이 제 안되어야 한다. 또한 현장에서 적용 시에는 보조자에 의 한 견갑 안정화 기법을 적용하여 스트레칭을 적용하고, 관절가동화 기법을 같이 적용할 것을 권장한다. 추가적 으로 자가 통제된 견갑골 안정화 기법을 적용한 스트레 칭 중재와 어깨안쪽돌림결핍에 관한 연구가 더욱 필요 할 것으로 생각된다. 그리고 어깨 어깨안쪽돌림결핍의 원인을 보다 명확하게 규명하기 위하여 낮은 굽힘 자세 의 가동 범위 측정을 포함할 것을 권장한다.

\section{Conflicts of Interest}

The authors declare no conflict of interest.

\section{References}

1. Jo YJ, Kim YK. Different types of shoulder injuries of throwing and resistance training groups. Asian J Kinesiol. 2016; 18 (3):73-83.

2. Burkhart SS, Morgan CD, Kibler WB. The disabled throwing shoulder: spectrum of pathology Part I: pathoanatomy and biomechanics. Arthroscopy. 2003; 19 (4):404-20.

3. Cools AM, Palmans T, Johansson FR. Age-related, sportspecific adaptions of the shoulder girdle in elite adolescent tennis players. J Athl Train. 2014; 49 (5):64753.

4. Kim YK, Park IY. The Relationships of Humerus Retroversion and Range of Motion associated with Baseball Career in the Throwing Shoulder. Asian J Kinesiol. 2010; 12(3):89-96.

5. Laudner KG, Moline MT, Meister K. The relationship between forward scapular posture and posterior shoulder tightness among baseball players. Am J Sports Med. 2010; 38(10):2106-12.

6. Reinold MM, Wilk KE, Macrina LC, et al. Changes in shoulder and elbow passive range of motion after pitching in professional baseball players. Am J Sports Med. 2008; 36(3):523-7.

7. Laudner KG, Lynall R, Meister K. Shoulder adaptations among pitchers and position players over the course of a competitive baseball season. Clin J Sport Med. 2013;
23(3):184-9.

8. Myers JB, Laudner KG, Pasquale MR, Bradley JP, Lephart SM. Glenohumeral range of motion deficits and posterior shoulder tightness in throwers with pathologic internal impingement. Am J Sports Med. 2006; 34(3):385-91.

9. Muraki T, Yamamoto N, Zhao KD, et al. Effects of posterior capsule tightness on subacromial contact behavior during shoulder motions. J Shoulder Elbow Surg. 2012; 21(9):1160-7.

10. Tyler TF, Nicholas SJ, Lee SJ, Mullaney M, McHugh MP. Correction of posterior shoulder tightness is associated with symptom resolution in patients with internal impingement. Am J Sports Med. 2010; 38(1):114-9.

11. Grossman MG, Tibone JE, McGarry MH, Schneider DJ, Veneziani S, Lee TQ. A cadaveric model of the throwing shoulder: a possible etiology of superior labrum anterior-to-posterior lesions. J Bone Joint Surg Am. 2005; 87(4):824-31.

12. Muraki T, Yamamoto N, Zhao KD, et al. Effect of posteroinferior capsule tightness on contact pressure and area beneath the coracoacromial arch during pitching motion. Am J Sports Med. 2010; 38(3):600-7.

13. Amin NH, Ryan J, Fening SD, Soloff L, Schickendantz MS, Jones M. The relationship between glenohumeral internal rotational deficits, total range of motion, and shoulder strength in professional baseball pitchers. J Am Acad Orthop Surg. 2015; 23(12):789-96.

14. Moher D, Liberati A, Tetzlaff J, Altman DG. Preferred reporting items for systematic reviews and metaanalyses: the PRISMA statement. Int J Surg. 2010; 8(5):336-41.

15. Guney H, Karabicak GO, Pekyavas NO, et al. Which stretching technique is effective in decreasing glenohumeral internal rotation deficit?. Med Sport. 2015; 68:291-302.

16. Hammons D, McChesney JW, Curtin M, Pfeiffer R, Thiede KW. Randomized and Blinded Study for the Treatment of Glenohumeral Internal Rotation of Motion Restriction: The Prone-Passive Stretching Technique. Official J Sports Med Allied Health Sci. 2015; 1(2):1-9 
17. Laudner KG, Sipes RC, Wilson JT. The acute effects of sleeper stretches on shoulder range of motion. J Athl Train. 2008; 43(4):359-63.

18. Maenhout A, Van Eessel V, Van Dyck L, Vanraes A, Cools A. Quantifying acromiohumeral distance in overhead athletes with glenohumeral internal rotation loss and the influence of a stretching program. Am J Sports Med. 2012; 40(9):2105-12.

19. McClure P, Balaicuis J, Heiland D, Broersma ME, Thorndike CK, Wood A. A randomized controlled comparison of stretching procedures for posterior shoulder tightness. J Orthop Sports Phys Ther. 2007; 37(3):108-14.

20. Yamauchi T, Hasegawa S, Nakamura M, et al. Effects of two stretching methods on shoulder range of motion and muscle stiffness in baseball players with posterior shoulder tightness: a randomized controlled trial. J Shoulder Elbow Surg. 2016; 25(9):1395-403.

21. Cools AM, Johansson FR, Cagnie B, Cambier DC, Witvrouw EE. Stretching the posterior shoulder structures in subjects with internal rotation deficit: comparison of two stretching techniques. J Shoulder Elbow. 2012; 4(1):56-63.

22. Manske RC, Meschke M, Porter A, Smith B, Reiman M. A randomized controlled single-blinded comparison of stretching versus stretching and joint mobilization for posterior shoulder tightness measured by internal rotation motion loss. Sports Health. 2010; 2(2):94-100.

23. Salamh PA, Kolber MJ, Hanney WJ. Effect of scapular stabilization during horizontal adduction stretching on passive internal rotation and posterior shoulder tightness in young women volleyball athletes: a randomized controlled trial. Arch Phys Med Rehabil. 2015; 96(2):349-56.

24. Borsa PA, Dover GC, Wilk KE, Reinold MM. Glenohumeral range of motion and stiffness in professional baseball pitchers. Med Sci Sports Exerc. 2006; 38(1):21-6.

25. Myers JB, Oyama S, Goerger BM, Rucinski TJ, Blackburn JT, Creighton RA. Influence of humeral torsion on interpretation of posterior shoulder tightness measures in overhead athletes. Clin J Sport Med. 2009; 19(5):36671.

26. Bailey LB, Shanley E, Hawkins R, et al. Mechanisms of shoulder range of motion deficits in asymptomatic baseball players. Am J Sports Med. 2015; 43(11):278393.

27. Tyler TF, Nicholas SJ, Lee SJ, Mullaney M, McHugh MP. Correction of posterior shoulder tightness is associated with symptom resolution in patients with internal impingement. Am J Sports Med. 2010; 38(1):114-9.

28. Borsa PA, Laudner KG, Sauers EL. Mobility and stability adaptations in the shoulder of the overhead athlete. Sports Med. 2008; 38(1):17-36.

29. Borstad JD, Dashottar A, Stoughton T. Validity and reliability of the Low Flexion measurement for posterior glenohumeral joint capsule tightness. Man Ther. 2015; 20(6):875-8.

30. Borstad JD, Dashottar A. Quantifying strain on posterior shoulder tissues during 5 simulated clinical tests: a cadaver study. J Orthop Sports Phys Ther. 2011; 41(2):90-9. 